$\Phi=-1$

\title{
Effectiveness of nursing interventions on level of anxiety, stress, and depression of elderly patients undergoing upper gastrointestinal endoscopy
}

\author{
Raefa Refaat Alam ${ }^{1} *$, Neamit Ibrahim Elemam Elashri ${ }^{2}$ \\ ${ }^{1}$ Assistant. Professor of Gerontological Nursing, Faculty of Nursing, Mansoura University, Egypt \\ ${ }^{2}$ Lecturer of Gerontological Nursing Faculty of Nursing, Mansoura University, Egypt \\ *Corresponding author E-mail: Neamaelashry@gmail.com
}

\begin{abstract}
Background: Gastrointestinal Endoscopy is a widely used procedure in medicine today. It is the diagnosis and treatment of choice among elderly patients with upper gastrointestinal disorders. Thus anxiety, stress, and depression of adverse out-come or side effect and discomfort regarding endoscopy reduce the patient's acceptance ability. Effective procedure ex-planation and safety measures have positively impact on decrease level of anxiety, stress, and depression and improve elderly patient's general health condition

Aim: Evaluate effectiveness of nursing interventions on level of anxiety, stress and depression of elderly patients undergoing upper gastrointestinal endoscopy.

Design: A quasi experimental study design with pre and post procedure was used.

Setting: The study was conducted at Gastrointestinal Surgery Center (GISC) (Endoscopy Unit) Mansoura University

Subjects: A convenient sample of 76 elderly patients undergoing GIT endoscopy. Data collected over a period of 9 months from first of May 2019 at the end of January 2020.

Tools: Three tools were used: Socio Demographic Characteristics and Clinical Data Structured Interview Schedule, Depression, Anxiety and Stress scales (DASS-21), and Endoscopic Nursing interventions.

Results: The study results revealed that statistically significant improvement in all aspects of elderly patient's anxiety score at pre and post nursing intervention $(\mathrm{p}<0.001)$. There were significant improvements of level of stress from pre and post implementation of nursing intervention to endoscopy $(\mathrm{p}<0.05)$. Also, there was a statistically significant difference in the pre, and posttest mean score of depression $(\mathrm{p}<0.05)$. Statistically significant differences regarding all sociodemographic characteristics within the studied subjects and their total mean score of anxiety, stress, and depression.

Conclusion A clear and noticeable improvement in the mean score of anxiety, stress and depression of all studied subject after the implementation of the endoscopic nursing interventions than before.

Recommendation: Replication of this study is highly recommended on a large representative probability sample to achieve generalizable results.
\end{abstract}

Keywords: Endoscopic Elderly; Nursing Intervention; Anxiety; Stress; and Depression.

\section{Introduction}

Anxiety consider one of the most common issues and problems confronting elderly patients undergoing operations or invasive diagnostic and therapeutic interventions (Arabul et al, 2012) and it is an effective and preventive factor in the resistance of the patients to do the operation (Sayah, 2013); several researches have proved that $80 \%$ of elderly patients older than 60 years old are diagnosed with different types of mental and physical illnesses. It also evidenced that $85 \%$ of these elderly diseases and illnesses related to anxiety (YeganehKhah et al., 2007). In several countries, various techniques are used to decrease anxiety in elderly patients prior operation; for example, mental counseling sessions, learning videos, patients communicating with individuals who have undergoing surgery before and playing music prior operations and making elderly patients familiar with staff and the operation room equipment are among efforts that have been studied in order to decrease anxiety prior operations (Elbashier \& Ali, 2019).

As a method, endoscopy is frequently studied in clinical reviews because of the several medical applications and expresses diagnostic advantages that it has. The fact of decreased side effects of endoscopy and possibility of sampling during it, applying this method is verified in the diagnosis of digestive illnesses (Enns et al., 2017). Numerous researches results are suggestive of occurrence of patient's severe anxiety and stress prior endoscopy.

Consequently, this side effect is not avoidable, and this means that individuals shall seek methods to reduce or eliminate it (Behrouzian et al, 2012). Anxiety causes a decrease disease tolerance and decreases individual's cooperation at endoscopy time with increase in patient's anxiety level, the time needed for diagnostic attempts increase and its side effects will rise and adversely the desirable outcome will be decreased (Anwar et al., 2018). 
There are a very large numbers of individuals who feel stress and anxiety with endoscopy and some efforts to eliminate their fear and worrisome are essential. With the removal of these feelings, endoscopy become easier for patients and physicians can do it without tension. This has obliged researchers to develop multiple preliminary interventions in order to assist elderly patients compatible with stressful and invasive techniques before using experimental techniques (Shekari, \& Salehi, 2016). Gastrointestinal endoscopy has a significant benefit clinically from two aspects: at first, it makes seeing several sections of the upper gastrointestinal tract for the physician and secondly, endoscopy makes doctors able to obtain biopsy sample and cytology (Kutluturkan et al, 2010). Presence of false beliefs involving choking possibility and presence of severe pain due to endoscopy or severe worrying about the likelihood of infection through endoscope exaggerates anxiety in these individuals. First of all, late visits because of anxiety induced by the possibility of malignant disease or worry from diagnostic attempts side effects specially endoscopy which cause deference of diagnosing and elderly patients damage (Gikas \& Triantafillidis, 2014).

Mental and physical reactions and responses on gastrointestinal methods is mainly affected by anxiety and endoscopy units should use strategies to decrease this anxiety. Elevated levels of anxiety can cause painful, incomplete and difficult endoscopy and elevates sedatives consumption. On one hand, stress and anxiety cause elevation of endoscopy duration and thus worsen the side effects caused by it. Therefore, reducing or preventing anxiety is influential throughout endoscopy (Kutluturkan et al, 2010).

Similarly, long time, severe and continues stress may cause destruction of the individuals and eventually cause mental and physical sicknesses (Reeve et al, 2013). Various studies have evidenced that continuous stress may rise the likelihood of incidence of mental disorders, stomach ulcers, myocardial infarction and other disorders related to health (Peixoto, Silva, Pereira, \& Macedo, 2016). Researches outcomes done in the past few years illustrates that rate and side effects of stress elevates to some extent that makes several organizations and institutes worry involving World Health Organization; in a way that the leading factor for individuals going to physicians is depression or stress (Kivimäki,\& Steptoe, 2018).

On the other hand, there is a relation among anxiety, stress, and depression in a manner that depression is more predominant in anxious and stressed patients and vice versa (Kloostra, Eber \& Inglehart, 2007). Previous researches results proved that anxiety, stress, and depression in elderly patients not affect only elderly patients' psychological condition, but it affects also elderly patients' quality of lives, return of the treatment, increase of the duration of hospital stay and even patient's age (Mystakidou et al, 2005). Researches have illustrated that doing invasive procedures such as endoscopy may aggravate anxiety and stress in elderly individuals and effective in feeling the intensity of pain (Behrouzian et al, 2012).

Therefore, since nurses spend most of their time with elderly patients than physicians, so her significant role in caring of the elderly patients cannot be denied. Implementing nursing intervention on elderly patients may cause decrease in anxiety, stress and depression of the elderly patients. The current study has been carried out for determining the effectiveness of nursing interventions on level of anxiety, stress, and depression for elderly patients with upper gastrointestinal endoscopy. Gastroscopy is a widely used procedure in medicine today. It is the diagnosis and treatment of choice among elderly patients with upper gastrointestinal disorders. Thus anxiety, stress, and depression of adverse outcome or side effect and discomfort regarding endoscopy reduce the patient's acceptance ability (Kurtluturkan et al, 2010). Therefore, effective procedure explanation and safety measures have positively impact on decrease level of anxiety, stress, and depression and improve elderly patient's general health condition. So, providing guidelines in the form of a pamphlet, brochures and video can minimize anxiety and other discomfort that endoscopy is indicated and reducing stress during the procedure.

\section{Aim of the study}

Evaluate the effectiveness of nursing interventions on level of anxiety, stress and depression of elderly patients undergoing upper gastrointestinal endoscopy

\section{Research hypothesis}

$\mathrm{H}^{1}$ : Elderly patients' level of anxiety, stress, and depression of upper gastrointestinal endoscopy means score will be significantly improved post implementation of the nursing interventions.

Research variables in the study are:

a) Independent variables: nursing interventions.

b) Dependent variables: level of anxiety, stress and depression of elderly patients.

\section{Method}

\subsection{Study design}

A quasi experimental study design with pre and post procedure was used in this study to fulfill the aims of this study.

\subsection{Setting}

This study was carried out at Gastrointestinal Surgery Center (GISC) (Endoscopy Unit) affiliated to Mansoura University, Dakahlia governorate-Egypt.

\subsection{Subjects}

The study involved a convenience sample of 76 elderly patients, drawn from all the patients waiting for endoscopic examination during a period from first May 2019 to the end of January 2020. The study subjects who were included were more than 60 years old who accepted to be involved and didn't have past history of mental disorder or drugs consumption related to these diseases as documented on patient's files, haven't previously had experienced endoscopy and haven't had administered sedatives the night prior endoscopy. Elderly patients with gastrointestinal complications, speech disorder, who are sedated/confused and end stage of liver, were excluded.

\subsection{Tools}


Three tools were used to collect the necessary data

Tool I: Socio Demographic Characteristics and Clinical Data Structured Interview Schedule

This tool was developed by the researcher based on review of relevant literature; it divided into two parts: Part I: Socio demographic characteristics of the study subjects such as age, gender, educational level, occupation before retirement and income, source of income, living arrangement. Part II: Medical history of the study subjects such as history of chronic disease and numbers of present chronic diseases, pervious hospitalization in the last year, duration of endoscopy, number of medications and complication.... etc.

Tool II: Depression, Anxiety and Stress scales (DASS-21)

This tool measures the intensity of anxiety, stress, and depression of the patients. It has been developed by (Lovibound et al, 1995). And it also has 21 phrases in which each of the mental items' "depression", "anxiety" and "stress" were evaluated through seven different sentences. Each of the three DASS-21 scales contains 7 items, divided into subscales with similar content. The depression scale assesses dysphoria, hopelessness, devaluation of life, self-deprecation, lack of interest/ involvement, anhedonia and. The anxiety scale assesses autonomic arousal, skeletal muscle effects, situational anxiety, and subjective experience of anxious affect. The stress scale is sensitive to levels of chronic nonspecific arousal. It assesses difficulty relaxing, nervous arousal, and being easily upset/ agitated, irritable/ overreactive and impatient. Scores for depression, anxiety and stress are calculated by summing the scores for the relevant items. Possible scores range from range from 0 to 126 , higher scores indicate higher anxiety, stress and depression level. DASS requires approximately 15-20 minutes completing.

Tool III: Endoscopic Nursing interventions:

It was prepared by the researcher based on literature review. Involving education about the preparations prior, during and post endoscopy, offering the elderly patient the opportunity to share their feelings and ask about their concerns, replying on the elderly patients' questions, discussing endoscopy details and analyzing the emotions and reactions of the elderly patient, teaching them how to perform deep breathing and positive mental reinforcement to support them. Consulting a psychology, using religious books, and spiritual support can be useful if needed.

\subsection{Procedure}

1) Validity and reliability of the tools: Validity of tools was done by 7 experts from medical and gerontological nursing field to check the relevancy, clarity, comprehensiveness, and applicability of the questions. According to their opinions, minor modifications were done, and the final form was developed. The reliability of the tool II (DASS-21) was tested using the internal consistency method Cronbach's alpha reliability coefficient was $\mathrm{r}=0.85$.

2) Pilot Study: The Arabic versions of the tools were carried out on $10 \%$ (7) of the study subjects to test and ascertain clarity and feasibility of the study tools. The elderly patients who were included in the pilot study were excluded from the study sample.

3) Field Work:

Data were collected in the following sequence:

a) Assessment phase: the study protocol was approved and an official permission from hospital director to carry out the study after identification of the purpose of the study. Data were collected throughout two phases of assessment by using two tools. The first phase of assessment was collected prior to conducting the nursing interventions to have base line data about elderly patient condition, observe and measure patient outcome through anxiety, stress and depression level for procedure.

b) Planning Phase: Development of the nursing interventions pamphlet based on analysis of the collected data. It was developed guided by reviewing the most recent related literature; the researchers developed this pamphlet in simple Arabic language with colored pictures and large sized font to accommodate age related visual changes to enhance the elderly learning ability in addition to using teaching aids and media such as video.

c) Implementation phase: data were collected at endoscopy unit at Gastrointestinal Surgery Center. Data collection covered a period of 9 months, the proposed interventions covered by 4 sessions ( 2 sessions for information, one session pretest and one session posttest). Each session takes 20-30 minutes; number of elderly patients in each session included three elderly patients or individualized patients. Education regarding the procedure of upper GI endoscopy was administered to all elderly patients. Initially they were proved a video depicting procedure of endoscopy, instruments used and associated discomfort. In addition to, explaining preparation, steps of procedure during endoscopy and post endoscopic care.

d) Evaluation phase: the last phase of the nursing interventions. Each elderly patient was evaluated two times. First, before starting the endoscopic procedure, and secondly upon discharge. Pre-examination phase were elicited demographic data, stress, depression and anxiety level. The second step was accomplished after endoscopy and on discharge and involved elderly patients' depression, anxiety, and stress level as primary outcome was estimated by the researcher using tool around 1-2 hour after take-off the endoscopy.

\subsection{Ethical considerations}

The researcher approached elderly patients individually at endoscopy unit and explaining the purpose of the study. Elderly patients who were willing to participate were included in the study after obtaining their oral consent. Confidentiality of all information was secured.

\section{Statistical Analysis}

After compiling of data collection variables included in each data assessment sheet were coded and scored manually before data entry. Descriptive statistics (frequency, mean, percentage and standard deviation) were done for quantitative and qualitative variables and paired t-test was used for pre-post comparison. P value was considered significant if less than 0.05 . The above-mentioned statistical techniques were obtained by using the statistical package of social sciences SPSS.

\section{Results}

Table (1): showed that the $43.4 \%$ of the studied subject ranged from 65 to 70 years old and the Mean \pm SD for the age was $66.57 \pm 4.08,60.5 \%$ of them were male. Also, $47.4 \%$ were widowed. Regarding their level of education, $32.9 \%$ were illiterate, $76.3 \%$ of them were on pension. About $59.2 \%$ lived with partners, $77.6 \%$ had inadequate monthly income and $82.9 \%$ had no recent work. 
Table (2): illustrated that $52.6 \%$ of the studied subject had less than 3 chronic diseases and the same percentage were hospitalized once in the last year. Additionally, $44.7 \%$ received more than 5 types of medication, $60.5 \%$ spent more than 15 minutes in the procedure, and $31.6 \%$ were diagnosed with esophagitis and gastritis.

Table (3): showed comparison of demographic characteristics between pre and post intervention regarding the total mean score of anxiety, stress, and depression. Firstly, concerning anxiety, the overall mean score was $39.39 \pm 1.66$ for the pre-test intervention and $8.81 \pm 3.90$ for the post-test intervention $\left(\mathrm{p}_{2} 0.000^{*}\right)$ and there was strong statistically significant difference between pre and post intervention. Moreover, there were statistically significant differences regarding all soicodemgraphic characteristics $(\mathrm{p}=0.000 *)$. Secondly, regarding stress, the overall mean score was $38.18 \pm 2.44$ for the pre-test intervention and $9.73 \pm 5.77$ for the post-test intervention $(\mathrm{p}=0.000 *)$ and there was strong statistically significant difference between pre and post interventions. Moreover, there were statistically significant differences regarding all soicodemgraphic characteristics $\left(\mathrm{p}_{=}=0.000 *\right)$. Finally, regarding depression, the overall mean score was $37.47 \pm 2.85$ for the pre-test intervention and $8.26 \pm 4.47$ for the post-test intervention $\left(\mathrm{p}=0.000^{*}\right)$ and there was strong statistically significant difference between pre and post intervention. Moreover, there were statistically significant differences regarding all soicodemgraphic characteristics $(\mathrm{p}=0.000 *)$.

Table 4: showed comparison of health history between pre and post intervention regarding the total mean score of anxiety, stress, and depression. There were statistically significant differences regarding all items of health history $(\mathrm{p}=0.000 *)$.

Table 5: illustrated that all studied subject suffered from extremely severe anxiety before the implementation of the endoscopic nursing intervention and mean \pm SD was $39.39 \pm 1.66$. On the other hand, $83.2 \%$ of them were normal post the implementation with mean \pm SD $8.81 \pm 3.90$ and there is a strong statistically significance difference between the two groups. Regarding stress $98.7 \%$ of them suffered from extremely severe stress before the implementation of the endoscopic nursing intervention with mean \pm SD $38.18 \pm 2.44$, but $82.9 \%$ were normal after the intervention with mean \pm SD $9.73 \pm 5.77$ and there were a strong statistically significance difference between pre and post intervention. Furthermore, concerning depression all studied subject suffered from extremely severe depression before the implementation of the endoscopic nursing intervention and mean $\pm \mathrm{SD}$ was $37.47 \pm 2.85$ but $51.3 \%$ of them were normal after the implementation of the intervention and there mean \pm SD was $8.26 \pm 4.47$ and a strong statistically significance difference was detected.

Table 1: Socio Demographic and Medical Characteristics of Elderly Patients with Upper Gastrointestinal Endoscopy

\begin{tabular}{|c|c|c|}
\hline 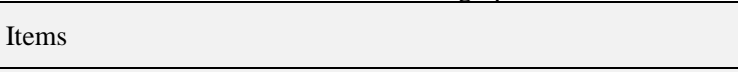 & $\begin{array}{l}\text { Study Subjects } \\
\mathrm{n}_{=} 76\end{array}$ & $\%$ \\
\hline \multicolumn{3}{|l|}{ Age (in year): } \\
\hline $60-65$ & 25 & 32.9 \\
\hline $65-70$ & 33 & 43.4 \\
\hline $70+$ & 18 & 23.7 \\
\hline \multicolumn{3}{|l|}{$($ Mean \pm SD $)=66.57 \pm 4.08)$ Minimum $=60 \mathrm{yrs}-$ Maximum 76.0yrs } \\
\hline \multicolumn{3}{|l|}{ Sex: } \\
\hline Males & 46 & 60.5 \\
\hline \multicolumn{3}{|l|}{ Marital status: } \\
\hline Married & 26 & 34.2 \\
\hline Widowed & 36 & 47.4 \\
\hline Divorced & 14 & 18.4 \\
\hline \multicolumn{3}{|l|}{ Level of education: } \\
\hline Illiterate & 25 & 32.9 \\
\hline Read and write & 20 & 26.3 \\
\hline primary level & 13 & 17.1 \\
\hline University and higher level & 7 & 9.2 \\
\hline \multicolumn{3}{|l|}{ Source of income: } \\
\hline Pension & 58 & 76.3 \\
\hline Relatives and Friends & 0 & 0.0 \\
\hline Social affairs & 6 & 7.9 \\
\hline Sons Help & 12 & 15.8 \\
\hline \multicolumn{3}{|l|}{ Live with } \\
\hline Alone & 11 & 14.5 \\
\hline With partner & 45 & 59.2 \\
\hline Within family & 4 & 5.3 \\
\hline With their sons & 16 & 21.1 \\
\hline \multicolumn{3}{|l|}{ Monthly income: } \\
\hline Adequate & 17 & 22.4 \\
\hline Inadequate & 59 & 77.6 \\
\hline \multicolumn{3}{|l|}{ Recent work } \\
\hline Yes & 13 & 17.1 \\
\hline No & 63 & 82.9 \\
\hline
\end{tabular}

Table 2: Health History of Elderly Patients with Upper Gastrointestinal Endoscopy (N=76)

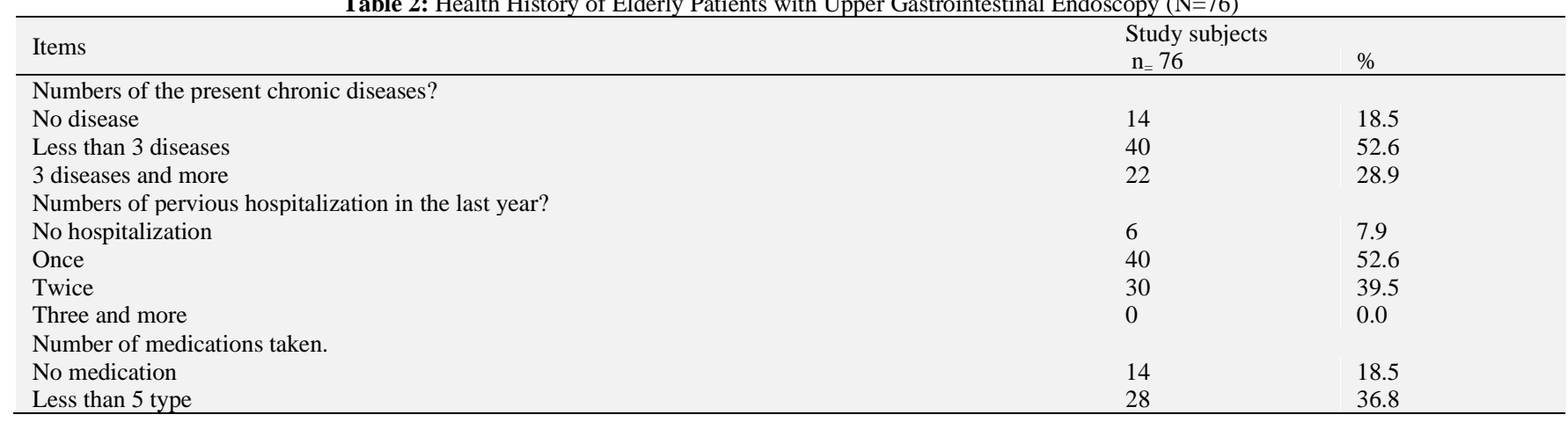




\begin{tabular}{lc}
\hline More than 5 type & 34 \\
Procedure duration & 44.7 \\
Less than 15 min & 39.5 \\
More than 15 min & 60.5 \\
Diagnosis: & 46 \\
Esophagitis & 31.6 \\
Gastritis & 31.6 \\
Gastro duodenal ulcer & 17.1 \\
Esophageal varicies & 19.7 \\
\hline
\end{tabular}

Table 3: Comparison of Demographic Characteristics between Subjects before and After Implementation of Endoscopic Nursing Interventions Regarding the Total Mean Score of Anxiety, Stress, and Depression

\begin{tabular}{|c|c|c|c|c|c|c|c|c|c|c|}
\hline \multirow{2}{*}{$\begin{array}{l}\text { Demographic } \\
\text { Characteris- } \\
\text { tics }\end{array}$} & \multirow[b]{2}{*}{$\mathrm{N}$} & \multicolumn{3}{|c|}{ Anxiety $($ Mean \pm SD) } & \multicolumn{3}{|c|}{ Stress (Mean \pm SD) } & \multicolumn{3}{|c|}{ Depression (Mean \pm SD) } \\
\hline & & \multicolumn{2}{|l|}{ Pretest } & Posttest & pretest & \multicolumn{2}{|c|}{ Posttest } & pretest & \multicolumn{2}{|l|}{ Posttest } \\
\hline $\begin{array}{l}\text { Overall mean } \\
\text { score }\end{array}$ & 7 & \multicolumn{2}{|l|}{$39.39 \pm 1.66$} & $\begin{array}{l}8.81 \pm 3.9 \\
0\end{array}$ & $38.18 \pm 2.44$ & \multicolumn{2}{|c|}{$9.73 \pm 5.77$} & $\begin{array}{l}37.47 \pm 2.8 \\
5\end{array}$ & \multicolumn{2}{|l|}{$8.26 \pm 4.47$} \\
\hline p- value & 6 & \multicolumn{2}{|c|}{$\mathrm{T}_{=} 66.910 \mathrm{p}=(0.000) *$} & & \multicolumn{3}{|c|}{$\mathrm{T}_{=} 36.314 \mathrm{p}=(0.000) *$} & \multicolumn{3}{|c|}{$\mathrm{T}=38.36 \mathrm{p}=(0.000) *$} \\
\hline Age (years): & & Pretest & posttest & $\mathrm{P}^{1}$ - value & pretest & posttest & $\begin{array}{l}\mathrm{P}^{2}- \\
\text { value }\end{array}$ & pretest & posttest & $\mathrm{P}^{3}$ - value \\
\hline $60-$ & $\begin{array}{l}2 \\
5\end{array}$ & $\begin{array}{l}38.72 \pm 1.7 \\
2\end{array}$ & $5.36 \pm 1.70$ & $\begin{array}{l}\mathrm{T}=49.03 \\
\mathrm{p}=0.000\end{array}$ & $\begin{array}{l}39.92 \pm 2.0 \\
3\end{array}$ & $6.48 \pm 2.40$ & $\begin{array}{l}\mathrm{T}=40.34 \\
\mathrm{p}=0.000\end{array}$ & $\begin{array}{l}38.80 \pm 1.4 \\
1\end{array}$ & $6.16 \pm 5.85$ & $\begin{array}{l}\mathrm{T}=23.57 \\
\mathrm{p}=0.000\end{array}$ \\
\hline $65-$ & $\begin{array}{l}3 \\
3\end{array}$ & $\begin{array}{l}40.24 \pm 1.0 \\
9\end{array}$ & $\begin{array}{l}11.93 \pm 3.4 \\
8\end{array}$ & $\begin{array}{l}\mathrm{T}=42.29 \\
\mathrm{p}=0.000\end{array}$ & $\begin{array}{l}37.69 \pm 2.5 \\
5\end{array}$ & $10.90 \pm 7.53$ & $\begin{array}{l}\mathrm{T}=19.99 \\
\mathrm{p}=0.000\end{array}$ & $\begin{array}{l}37.93 \pm 3.3 \\
3\end{array}$ & $9.57 \pm 3.73$ & $\begin{array}{l}\mathrm{T}=23.73 \\
\mathrm{p}=0.000\end{array}$ \\
\hline $70+$ & $\begin{array}{l}1 \\
8\end{array}$ & $\begin{array}{l}38.77 \pm 1.8 \\
3\end{array}$ & $7.88 \pm 1.74$ & $\begin{array}{l}\mathrm{T}=62.90 \\
\mathrm{p}_{2}=0.000\end{array}$ & $\begin{array}{l}36.66 \pm 0.9 \\
7\end{array}$ & $12.11 \pm 2.78$ & $\begin{array}{l}\mathrm{T}=27.81 \\
\mathrm{p}=0.000\end{array}$ & $\begin{array}{l}34.77 \pm 1.2 \\
1\end{array}$ & $8.77 \pm 1.83$ & $\begin{array}{l}\mathrm{T}=37.90 \\
\mathrm{p}=0.000\end{array}$ \\
\hline Female & $\begin{array}{l}3 \\
0\end{array}$ & $\begin{array}{l}38.46 \pm 1.4 \\
5\end{array}$ & $5.60 \pm 1.92$ & $\begin{array}{l}\mathrm{T}=50.83 \\
\mathrm{p}=0.000\end{array}$ & $\begin{array}{l}39.60 \pm 1.9 \\
9\end{array}$ & $6.73 \pm 2.25$ & $\begin{array}{l}\mathrm{T}=25.36 \\
\mathrm{p}=0.000\end{array}$ & $\begin{array}{l}38.46 \pm 1.4 \\
5\end{array}$ & $6.20 \pm 5.33$ & $\begin{array}{l}\mathrm{T}=30.24 \\
\mathrm{p}=0.000\end{array}$ \\
\hline $\begin{array}{l}\text { Marital sta- } \\
\text { tus: }\end{array}$ & & & & & & & & & & \\
\hline Married & $\begin{array}{l}2 \\
6\end{array}$ & $\begin{array}{l}39.00 \pm 1.8 \\
1\end{array}$ & $8.30 \pm 2.31$ & $\begin{array}{l}\mathrm{T}=76.90 \\
\mathrm{p}_{2}=0.000\end{array}$ & $\begin{array}{l}37.30 \pm 2.3 \\
9\end{array}$ & $6.30 \pm 2.09$ & $\begin{array}{l}\mathrm{T}=52.57 \\
\mathrm{p}=0.000\end{array}$ & $\begin{array}{l}39.07 \pm 1.7 \\
1\end{array}$ & $8.00 \pm 2.65$ & $\begin{array}{l}\mathrm{T}=45.90 \\
\mathrm{p}=0.000\end{array}$ \\
\hline Widow & $\begin{array}{l}3 \\
6\end{array}$ & $\begin{array}{l}39.66 \pm 1.2 \\
1\end{array}$ & $9.72 \pm 4.48$ & $\begin{array}{l}\mathrm{T}=41.12, \\
\mathrm{p}_{=} 0.000\end{array}$ & $\begin{array}{l}38.05 \pm 2.1 \\
6\end{array}$ & $12.77 \pm 6.07$ & $\begin{array}{l}\mathrm{T}=20.86 \\
\mathrm{p}=0.000\end{array}$ & $\begin{array}{l}36.00 \pm 2.7 \\
4\end{array}$ & $9.27 \pm 4.78$ & $\begin{array}{l}\mathrm{T}=22.55 \\
\mathrm{p}=0.000\end{array}$ \\
\hline Divorced & $\begin{array}{l}1 \\
4\end{array}$ & $\begin{array}{l}39.42 \pm 2.4 \\
0\end{array}$ & $7.42 \pm 4.32$ & $\begin{array}{l}\mathrm{T}=22.26 \\
\mathrm{p}=0.000\end{array}$ & $\begin{array}{l}40.14 \pm 2.2 \\
8\end{array}$ & $8.28 \pm 5.75$ & $\begin{array}{l}\mathrm{T}=15.55 \\
\mathrm{p}=0.000\end{array}$ & $\begin{array}{l}38.28 \pm 3.0 \\
2\end{array}$ & $6.14 \pm 5.68$ & $\begin{array}{l}\mathrm{T}=15.29 \\
\mathrm{p}=0.000\end{array}$ \\
\hline Illiterate & $\begin{array}{l}2 \\
5\end{array}$ & $\begin{array}{l}38.96 \pm 1.0 \\
1\end{array}$ & $5.44 \pm 2.04$ & $\begin{array}{l}\mathrm{T}=60.16, \\
\mathrm{p}=0.000\end{array}$ & $\begin{array}{l}39.92 \pm 2.0 \\
3\end{array}$ & $6.48 \pm 2.40$ & $\begin{array}{l}\mathrm{T}=40.34 \\
\mathrm{p}=0.000\end{array}$ & $38.96 \pm 1.01$ & $\begin{array}{l}6.24 \pm 5 . \\
86\end{array}$ & $\begin{array}{l}\mathrm{T}=23.7 \\
\mathrm{p}=0.000\end{array}$ \\
\hline $\begin{array}{l}\text { Read and } \\
\text { write }\end{array}$ & $\begin{array}{l}2 \\
0\end{array}$ & $\begin{array}{l}39.50 \pm 2.2 \\
3\end{array}$ & $8.60 \pm 1.60$ & $\begin{array}{l}\mathrm{T}=73.15 \\
\mathrm{p}=0.000\end{array}$ & $\begin{array}{l}38.00 \pm 2.5 \\
1\end{array}$ & $5.50 \pm 1.70$ & $\begin{array}{l}\mathrm{T}=65.00 \\
\mathrm{p}=0.000\end{array}$ & $39.50 \pm 2.23$ & $\begin{array}{l}6.60 \pm 0 . \\
94\end{array}$ & $\begin{array}{l}\mathrm{T}=82.93 \\
\mathrm{p}=0.000\end{array}$ \\
\hline Primary level & $\begin{array}{l}1 \\
3\end{array}$ & $\begin{array}{l}40.00 \pm 0.0 \\
0\end{array}$ & $\begin{array}{l}16.00 \pm 0.0 \\
0\end{array}$ & $\begin{array}{l}T=24.21 \\
p_{=}=0.000\end{array}$ & $\begin{array}{l}38.00 \pm 0.0 \\
0\end{array}$ & $\begin{array}{l}20.00 \pm 0.0 \\
0\end{array}$ & $\begin{array}{l}T=43.21 \\
p=0.000\end{array}$ & $34.00 \pm 0.00$ & $\begin{array}{l}14.00 \pm \\
0.00\end{array}$ & $\begin{array}{l}\mathrm{T}=63.01, \mathrm{p}_{=}=0.00 \\
0\end{array}$ \\
\hline $\begin{array}{l}\text { Secondary } \\
\text { level }\end{array}$ & $\begin{array}{l}1 \\
1\end{array}$ & $\begin{array}{l}39.27 \pm 2.4 \\
1\end{array}$ & $8.36 \pm 1.20$ & $\begin{array}{l}\mathrm{T}=28.33 \\
\mathrm{p}=0.000\end{array}$ & $\begin{array}{l}36.18 \pm 0.6 \\
0\end{array}$ & $\begin{array}{l}13.63 \pm 1.2 \\
0\end{array}$ & $\begin{array}{l}\mathrm{T}=41.33 \\
\mathrm{p}=0.000\end{array}$ & $34.00 \pm 0.00$ & $\begin{array}{l}9.63 \pm 1 . \\
20\end{array}$ & $\begin{array}{l}\mathrm{T}=67.00, \mathrm{p}_{=} 0.00 \\
0\end{array}$ \\
\hline $\begin{array}{l}\text { University } \\
\text { level } \\
\text { Monthly } \\
\text { income: }\end{array}$ & 7 & $\begin{array}{l}39.71 \pm 1.7 \\
9\end{array}$ & $8.87 \pm 1.95$ & $\begin{array}{l}T=41.82, \\
p=0.000\end{array}$ & $\begin{array}{l}36.00 \pm 3.4 \\
6\end{array}$ & $8.28 \pm 4.38$ & $\begin{array}{l}T=11.70 \\
p=0.000\end{array}$ & $38.28 \pm 3.14$ & $\begin{array}{l}7.42 \pm 2 . \\
22\end{array}$ & $\begin{array}{l}\mathrm{T}=17.22, \mathrm{p}=0.00 \\
0\end{array}$ \\
\hline Adequate & $\begin{array}{l}1 \\
7\end{array}$ & $\begin{array}{l}38.00 \pm 2.4 \\
4\end{array}$ & $8.35 \pm 3.62$ & $\begin{array}{l}\mathrm{T}=30.44, \\
\mathrm{p}=0.000\end{array}$ & $\begin{array}{l}37.41 \pm 2.6 \\
2\end{array}$ & $9.17 \pm 5.15$ & $\begin{array}{l}\mathrm{T}=18.90 \\
\mathrm{p}=0.000\end{array}$ & $\begin{array}{l}36.82 \pm 2.4 \\
5\end{array}$ & $7.05 \pm 4.00$ & $\begin{array}{l}\mathrm{T}=21.06, \mathrm{p}_{2}=0.00 \\
0\end{array}$ \\
\hline Inadequate & $\begin{array}{l}5 \\
9\end{array}$ & $\begin{array}{l}39.79 \pm 1.0 \\
9\end{array}$ & $8.94 \pm 4.00$ & $\begin{array}{l}T=59.70 \\
p=0.000\end{array}$ & $\begin{array}{l}38.40 \pm 2.3 \\
7\end{array}$ & $9.89 \pm 5.97$ & $\begin{array}{l}\mathrm{T}=30.83 \\
\mathrm{p}=0.000\end{array}$ & $\begin{array}{l}36.33 \pm 2.9 \\
5\end{array}$ & $8.61 \pm 4.56$ & $\begin{array}{l}\mathrm{T}=32.37, \mathrm{p}_{2}=0.00 \\
0\end{array}$ \\
\hline
\end{tabular}

(P) ${ }^{1}$ : comparing the total mean score of anxiety pre versus post interventions in each category.

(P) ${ }^{2}$ : comparing the total mean score of stress pre versus post interventions in each category.

(P) ${ }^{3}$ : comparing the total mean score of depression pre versus post interventions in each category.

Significant, at $\mathrm{P} \leq 0.001$.

Table 4: Comparison of the Studied Subject's Health History Before and After Implementation of Endoscopic Nursing Interventions Regarding the Total Means Score of Anxiety, Stress, and Depression

\begin{tabular}{|c|c|c|c|c|c|c|c|}
\hline health history & $\mathrm{N}$ & Anxiety (Mean \pm SD) & $\mathrm{P}^{1}$ - value & Stress $($ Mean \pm SD) & $\mathrm{P}^{2}$ - value & Depression $($ Mean \pm SD) & $\mathrm{P}^{3}$ - value \\
\hline nealth nistory & $\mathbf{N}$ & pretest Posttest & P-value & pretest posttest & & pretest posttest & P-value \\
\hline
\end{tabular}




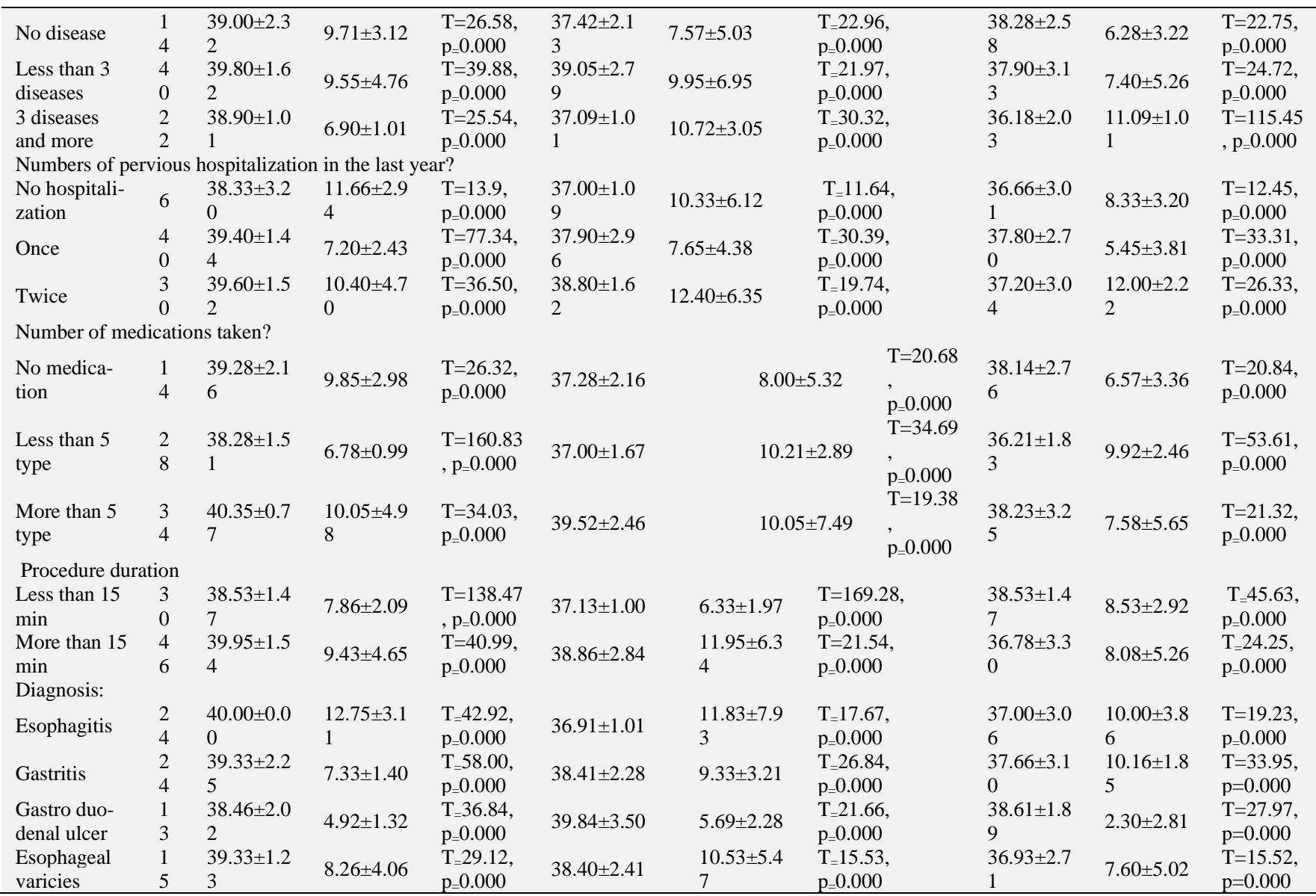

$(\mathrm{P})^{1}$ : comparing the total mean score of anxiety pre versus post interventions in each category.

$(\mathrm{P})^{2}$ : comparing the total mean score of stress pre versus post interventions in each category.

$(\mathrm{P})^{3}$ : comparing the total mean score of depression pre versus post interventions in each category.

Table 5: Comparison Between Anxiety, Stress, and Depression of the Studied Subjects Before and After Implementation of Endoscopic Nursing Interventions

\begin{tabular}{|c|c|c|c|c|c|c|c|c|c|c|c|c|c|c|c|c|c|c|c|}
\hline \multirow{3}{*}{$\begin{array}{l}\text { Item } \\
\text { Anxiety }\end{array}$} & \multicolumn{7}{|c|}{ Pre - intervention $\mathrm{N}_{7} 76$} & & & \multicolumn{10}{|c|}{ Post interventions $\mathrm{N}_{=} 76$} \\
\hline & Normal & \multicolumn{2}{|c|}{ Mild } & \multicolumn{2}{|c|}{ Moderate } & \multicolumn{2}{|c|}{ Severe } & \multicolumn{2}{|c|}{$\begin{array}{l}\text { Extremely } \\
\text { severe }\end{array}$} & \multicolumn{2}{|c|}{ Normal } & \multicolumn{2}{|c|}{ Mild } & \multicolumn{2}{|c|}{ Moderate } & \multicolumn{2}{|c|}{ Severe } & \multicolumn{2}{|c|}{$\begin{array}{l}\text { Extremely } \\
\text { severe }\end{array}$} \\
\hline & $\%$ & $\mathrm{~N}$ & $\%$ & $\mathrm{~N}$ & $\%$ & $\mathrm{~N}$ & $\%$ & $\mathrm{~N}$ & $\%$ & $\mathrm{~N}$ & $\%$ & $\mathrm{~N}$ & $\%$ & $\mathrm{~N}$ & $\%$ & $\mathrm{~N}$ & $\%$ & $\mathrm{~N}$ & $\%$ \\
\hline \multicolumn{10}{|c|}{ Anxiety $($ Mean \pm SD $)=39.39 \pm 1.66$} & \multicolumn{10}{|c|}{ Anxiety $($ Mean \pm SD $)=8.81 \pm 3.90$} \\
\hline $\mathrm{P}^{1}$ - value & \multicolumn{9}{|c|}{$\mathrm{T}_{=} 66.910 \mathrm{p}_{=}(0.000) *$} & & & & & & & & & & \\
\hline Stress & $0 \quad 0.0$ & 0 & 0.0 & 0 & 0.0 & 1 & 1.3 & 75 & 98.7 & 63 & 82.9 & 0 & 0.0 & 13 & 17.1 & 0 & 0.0 & 0 & 0.0 \\
\hline \multicolumn{10}{|c|}{ Stress $($ Mean \pm SD $)=38.18 \pm 2.44$} & \multicolumn{10}{|c|}{ Stress $($ Mean \pm SD $)=9.73 \pm 5.77$} \\
\hline $\mathrm{P}^{2}$ - value & \multicolumn{9}{|c|}{$\mathrm{T}_{=} 36.314 \mathrm{p}_{=}(0.000) *$} & & & & & & & & & & \\
\hline Depression & $0 \quad 0.0$ & 0 & 0.0 & 0 & 0.0 & 0 & 0.0 & 76 & 100 & 39 & 51.3 & 24 & 31.6 & 13 & 17.1 & 0 & 0.0 & 0 & 0.0 \\
\hline \multicolumn{10}{|c|}{ Depression (Mean \pm SD $37.47 \pm 2.85$} & \multicolumn{10}{|c|}{ Depression (Mean \pm SD) $8.26 \pm 4.47$} \\
\hline
\end{tabular}

$(\mathrm{P})^{1}$ : comparing the total mean score of anxiety pre versus post interventions using paired sample T-test.

(P) ${ }^{2}$ : comparing the total mean score of stress pre versus post interventions using paired sample T-test.

$(\mathrm{P})^{3}$ : comparing the total mean score of depression pre versus post interventions using paired sample T-test.

\section{Discussion}

Anxiety, stress and depression are psychological disorder that generated due to lack of knowledge regarding the procedure which may lead to the procedure become more difficult and painful. (Gebbensleben \& Rohde, 2012). Therefore, endoscopic nurse should offer a holistic package of nursing care to patients undergoing GI endoscopy through provides appropriate care before, during and after the procedure. Concerning age, around one half of the studied subjects are categorized as middle old that aged from 65 to 70 years with a mean of $66.57 \pm 4.08$ years. This finding can be explained to that age category are more exposed to predisposing factor of GIT problems, high consumption of coffee, cola, tea and misuse of over the counter medications such as excessive use of analgesics. This result is in consistent with Anwar, et al, (2018) who stated that more than one half of the subjects approximately aged between 51 to 60 years.

As for sex, males constituted two thirds of the studied subjects. This finding can be attributed to males are exposed to risk factors of gastric disorder such as smoking, alcoholism, stressful lifestyle and consume fast spicy foods which increase their susceptibility to digestive disorders in general. This result is congruent with the literature and the same result was reported by other studies that patients undergoing upper gastrointestinal endoscopy are predominantly males. Elhy \& Elalem (2017). Anwar, et al (2018). While Ghonaem \& Ibrahim (2019) contrary to the results of the current study that most of their subjects are females.

Regarding level of education; illiteracy was prevailing among one third of the studied subjects. This finding can be explained by lower educational level had negative effect on health, as illiterate elderly patients not seek medical care except in cases of necessity, still ignore 
any symptoms or any pain and related it to the effect of aging process. This was supported by a study done in Menoufia, Shibin Elkom by Elhy \& Elalem, (2017), in Assuit by Mh, et al (2014) \& in Tanata by Anwar, et al, (2018) mentioned that the majority of their studied subjects who undergoing upper gastrointestinal endoscopy was illiterate. Pervious studied reported the same finding (Ghonaem \& Ibrahim, 2019).

One half of the present study subject had at least of three chronic diseases with the same percentage were hospitalized once in the last year. This result is in equivalence with an Egyptian study done in Tanta, (2018) reported that than one third of studied patients had past medical history of liver, spleen and cancer and less than half had previous history of hospitalization. Another study done in India by Eberhardt, Van Wersch, Van Schaik, Cann (2019) reported that nearly one half of study samples were previously hospitalized.

With regards to duration of endoscopy procedure, nearly two thirds of the present studied subjects spent more than 15 minutes in their endoscopic procedure; This result was contradicted with $\mathrm{Ju}$-Yeon Lee, et al (2012) who reported that the inspection time mean of the endoscopy was $5.83 \pm 2.743$ minutes. Nearly two thirds of the present studied subjects had previously diagnosed with esophagitis and gastritis. This finding is in consistent with previous study done in Egypt Tanta (2018) mentioned that the most common indications of upper GI endoscopy include esophageal varices, upper GI erosions, peptic ulcer, esophagitis and upper GI tumors respectively of patients admitted to GI endoscopy units. This can be explained by most of Egyptian follow unhealthy lifestyle and more susceptible to GIT disturbance.

Anxiety, stress and depression lead to prolonged duration of endoscopy and increases its unexpected complications. Therefore, alleviation of anxiety and stress are important before GI endoscopy procedure.

The present study found that all studied subject suffered from extremely severe anxiety, stress and depression before the implementation of the endoscopic nursing intervention which changed to normal after the implementation of the intervention. This finding may be related to unawareness of elderly patients regarding procedure steps, fear of the procedure complications that may be happen; moreover, the negative rumors regarding the procedure. Furthermore, the effect of our intervention in reduction of anxiety, stress and depression level post intervention was valuable. Similar finding was reported by an Egyptian study done in Fayoum Mohammed, SA. (2016) which found that anxiety is more common among the patients subjected to endoscopy procedure. Also, another study done in Benha by Ghonaem \& Ibrahim (2019) reported that most of their subjects had severe anxiety and distress pre intervention and changed to mild anxiety and distress post interventions. The same findings were reported by a study done in Tanta (2018).

Moreover Gebbensleben \& Rohde (2012) were compatible with us; as they reported that two thirds of their patients experienced excessive anxiety before gastrointestinal endoscopy. In addition to a study done in Menofiya by Elhy\& Elalem, (2017) that most of studied sample had severe level of anxiety before endoscopy, while the majority of participant in study group had mild level of anxiety post early preparation regarding endoscopy.

Firstly, the overall mean score anxiety was improved after the intervention than before with a strong statistically significant difference. This result may be ought to the effect of the interventions which reduce patient's apprehension from the expected pain and complications and increase their awareness regarding procedure steps. Similar finding was reported by a study done in Fayoum Egypt by Mohammed, SA. (2016) as the mean anxiety score in the post test being less than the mean anxiety score in pretest after implementation of teaching guidelines. An Iranian study done by Behrouzian, et al (2012) mentioned that providing nursing consultation reducing the anxiety of patients before endoscopic examination. In equivalence with Kamyabi, et al (2016) who reported that patients in the information group experienced a significantly greater reduction in anxiety; combination of information and training prior to procedure is an effective means for reducing anxiety.

Also, this result is homogeneous with García Sierra, et al (2013) who found that nursing intervention was more effective in reducing patient anxiety. While thomas \& Sugirtha (2015) found that the mean anxiety score in the post test was significantly less than the mean anxiety score in pretest. Similar finding was reported by previous studies Maguire, et al (2004), Seda, Van, et al (2011). On the opposite side a Korean study, 2013 found that the level of anxiety in the treatment group were not significantly different from that in the comparison group (Kwon, Young-Eun, Kim, Bun-Han, 2013).

A case control study conducted by Pinar G et al (2011) found that pre-instructions did not cause a significant reduction in the anxiety level of the patients. Also, a study done by Uzbeck M et al (2009) reported that detailed risk information had greater increase in anxiety levels than those who received simple information. Furthermore, all studied subject of the present study revealed a clear and noticeable improvement in the depression mean score after the implementation of the endoscopic nursing intervention than before with a statistically significance difference was detected. This finding can be explained by there is a connection between depression, stress and anxiety in a way that depression is more prevalent in anxious and stressed patients and vice versa. In contrast with Shekari \& Salehi (2016) who found that the mean of score of depression has not a significant reduction after the experiment.

Most of the studied subject showed reduction level of stress after the implementation of the endoscopic nursing intervention than before with statistically significance difference between pre and post intervention. The results emphasized that the intervention is highly valuable and create positive effects on the stress level. Similar finding was reported by Shekari \& Salehi (2016) that the average of stress score in the experimental group before and after the experiment has been significantly reduced. Another study done by Behrouzian, et al (2012) reinforces that providing nursing consultation to endoscopic patients' lower rate of stress.

The present study revealed that the mean score of anxiety was significantly associated with all sociodemographic characteristics with statistically significant differences. This result is corresponding to the findings of Jones MP et al. also other study conducted by Eberhardt J et al, 2006 found that gender had an influence on the anxiety levels of the patient as female patients were more anxious than male patients.

However, Thomas \& Sugirtha (2015) come up with the opposite result that anxiety was not significantly associated with demographic variables like age, sex, educational qualification or marital status. While Shekari \& Salehi (2016) reported that the intensity of anxiety after the experiment in comparison with before it in the patients younger than 70 years old has been significantly decreased but no significant difference was seen in patients who are 70 years old or older. Anxiety intensity after the experiment in male patients significantly decreased but its changes in female patients was not significant. Also, the decline in anxiety level was significant in married than single. Regarding education, decrease in anxiety level after the intervention was higher and significant in the group of people without diploma and those with diplomas and finally, the decrease in the anxiety level based on work also has a significant difference and it has had a significant decrease in employed and unemployed patients.

As for the relationship between the total mean score of stress, depression and demographic characteristics, the present study showed that there were statistically significant differences regarding all sociodemographic characteristics within the studied subjects. This finding is in contradict with the findings of Shekari \& Salehi (2016) who assert on the score of stress after the intervention in comparison with before didn't have a significant difference based on all of the demographic variables. Moreover, the changes of the intensity of depression haven't had a significant difference based on any of the demographic variables. 


\section{Conclusion}

A clear and noticeable improvement in the mean score of anxiety, stress and depression of all studied subject after the implementation of the endoscopic nursing intervention than before it with a strong statistically significance difference. Endoscopic nursing care is an effective strategy in improving the level of anxiety, stress and depression of the elderly patients undergoing upper gastrointestinal endoscopy.

\section{Recommendations}

1) Application of nursing care interventions before gastrointestinal endoscopy as standardized care of the patients undergoing the invasive diagnostic methods.

2) Improving nurses' knowledge and practice through continued nursing education and in-service training programs in the endoscopic gastroenterology center should be organized regularly and the nurses should use pre, post nursing teaching guidelines according to protocol for caring with elderly patient undergoing upper GI endoscopy.

\section{Acknowledgement}

Special thanks and gratitude are offered to the medical staff in Gastrointestinal Surgery Center (GISC) (Endoscopy Unit) affiliated to Mansoura University, Egypt for their cooperation and support during conducting this study

\section{References}

[1] Anwar, S. A., Basal, A. A., Selim, M. F., \& Al-Metyazidy, H. A. Relation between Knowledge and Anxiety Level of Patients Under-going Upper Gastrointestinal Endoscopy at Tanta University Hospital.2018. https://doi.org/10.21608/tsnj.2018.71027.

[2] Arabul M, Kandemir A, M Celik, Alper E, Z Akpinar, Aslan M, Vatansever S. 2012. Impacto de un video de información antes de la colonoscopia en la satisfacción del paciente y la ansiedad. Turk J Gastroenterol, 23: 523-9. https://doi.org/10.4318/tjg.2012.0416.

[3] Behrouzian, F., Sadrizadeh, N., Nematpour, S., Seyedian, S. S., Nassiryan, M., \& Zadeh, A. J. F. (2017). The effect of psychological preparation on the level of anxiety before upper gastrointestinal endoscopy. Journal of clinical and diagnostic research: JCDR, 11(7), VC01. https://doi.org/10.7860/JCDR/2017/24876.10270.

[4] Bhosale, T. S., Bhosale, S. B., Zagade, T. B., \& Kakade, S. V. (2019). A study to assess effectiveness of video assisted teaching programme on gastrointestinal tract assessment among student nurses of tertiary care hospital: a statistical approach. International Journal of Research in Medical Sciences, 7(7), 2764. https://doi.org/10.18203/2320-6012.ijrms20192915.

[5] Eberhardt J, Van Wersch A, Van Schaik P, Cann P. Information, social support and anxiety before gastrointestinal endoscopy. British Journal of Health Psychology 2006 Nov;11(4):551-9. https://doi.org/10.1348/135910705X72514.

[6] Elbashier, I. M., \& Ali, K. M. (2019). Effectiveness of Psycho-Educational Program on Psychological Outcomes among Patients Undergoing Cardiac Surgery in Khartoum-2017. Nur Primary Care, 3(1), 1-5. https://doi.org/10.33425/2639-9474.1091.

[7] Elhy, A. H. A., \& Elalem, S. M. A. (2017). Effect of Early Preparation on Anxiety Level Among Patients Undergoing Upper Gas-trointestinal Endoscopy. American Journal of Nursing Science, 6(3), 202. https://doi.org/10.11648/j.ajns.20170603.18.

[8] Enns, R. A., Hookey, L., Armstrong, D., Bernstein, C. N., Heitman, S. J., Teshima, C., \& Sadowski, D. (2017). Clinical practice guidelines for the use of video capsule endoscopy. Gastroenterology, 152(3), 497-514. https://doi.org/10.1053/j.gastro.2016.12.032.

[9] García Sierra, R., Caballero Sáez, Y., \& Mena Sánchez, R. (2013). Anxiety in gastroscopies: Comparison of two nursing interventions in endoscopy without sedation. Enfermería Global [Revista en internet], 12(4), 41-50. https://doi.org/10.6018/eglobal.12.4.170561.

[10] Gebbensleben, B., \& Rohde, H., (2012). Anxiety before gastrointestinal endoscopy is a significant problem, Dtsch Med Wochenschr, 115(41):1539-44. https://doi.org/10.1055/s-2008-1065188.

[11] Ghonaem, S. E. S., \& Ibrahim, S. R. (2019). The effectiveness of behavioral intervention on anxiety and distress levels among upper gastroscopy patients. Am. J. Nurs. Res, 7, 58-64.

[12] Gikas, A., \& Triantafillidis, J. K. (2014). The role of primary care physicians in early diagnosis and treatment of chronic gastrointestinal diseases. International journal of general medicine, 7, 159. https://doi.org/10.2147/IJGM.S58888.

[13] Jones MP, Ebert CC, Sloan T, et al. Patient anxiety and elective gastrointestinal endoscopy. J Clin Gastroenterol 2004 Jan; 38(1):35-40. https://doi.org/10.1097/00004836-200401000-00009.

[14] Kivimäki, M., \& Steptoe, A. (2018). Effects of stress on the development and progression of cardiovascular disease. Nature Reviews Cardiology, 15(4), 215. https://doi.org/10.1038/nrcardio.2017.189.

[15] Kurtluturkan, S., Gorgulu, U., Fesci, H., \& Karavelioglu, A. (2010). The effects of providing pre- gastrointestinal endoscopy writ-ten educational material on patients, anxiety: A randomized control trail. international journal of nursing studies, 47(9), 1066-1073. 15 https://doi.org/10.1016/j.ijnurstu.2010.01.007.

[16] Kwon, Young-Eun1 · Kim, Bun-Han, 2013: The Effects of Video-audio Information Provision on Physical Discomfort, Anxiety, and Nursing Satisfaction of the Clients for Gastroscopy Korean J Adult Nurs Vol. 25 No. 2, 231-239, April 2013. https://doi.org/10.7475/kjan.2013.25.2.231.

[17] Lee, Ju-Yeon, Min-Whon Anhn, Eun-Tae Kim, Dae-Hyun Kim, Hyuk-Jung Kweon, Dong-Yung Cho, and Hyung Moon Yoon. "The effect of preparatory education program on discomfort and retching of examinees during upper gastrointestinal endoscopy." Korean journal of family medicine 33, no. 4 (2012): 219. https://doi.org/10.4082/kjfm.2012.33.4.219.

[18] Kamyabi, N., Nakhaei, M., Nasiri, A., Akbari, E., \& Sharifzadeh, G. (2016). Effects of video-and pamphlet-based patient educations on anxiety and satisfaction among candidates for gastroscopy. Modern Care Journal, 13(2). https://doi.org/10.17795/modernc.10647.

[19] Kloostra, P. W., Eber, R. M., \& Inglehart, M. R. (2007). Anxiety, stress, depression, and patients' responses to periodontal treatment: periodontists' knowledge and professional behavior. Journal of periodontology, 78(1), 64-71. https://doi.org/10.1902/jop.2007.060069.

[20] Lovibond, S.H. \&Lovibond, P.F. (1995). Manual for the Depression Anxiety \& Stress Scales. 2 nd Ed. Sydney: Psychology Foundation. https://doi.org/10.1037/t01004-000.

[21] Maguire a, J.C Deirdre. Walsh a, C.L. Little (2004) The effect of information and behavioral training on endoscopy patients' clinical out-comes Patient Education and Counseling 54 61-65. https://doi.org/10.1016/S0738-3991(03)00195-2.

[22] Mohammed, S. A. (2016). Effectiveness of structured teaching program on knowledge, anxiety state and tolerance for patients with gastrointestinal endoscopy: randomized controlled trial. Life Science Journal, 13(9).

[23] Mystakidou K, Silikat, papá E, E Katsouda, Galandos A, Vlahos L. 2005.Assessment de ansiedad y depresión en pacientes con cánceravanzado y surelación con la calidad de vida. Quality of Life Research, 14 )8): 1825-30. https://doi.org/10.1007/s11136-005-4324-3.

[24] Peixoto, A., Silva, M., Pereira, P., \& Macedo, G. (2016). Biopsies in gastrointestinal endoscopy: when and how. GE Portuguese journal of gastroenterology, 23(1), 19-27. https://doi.org/10.1016/j.jpge.2015.07.004.

[25] Pinar G, Kurt A, Gungor T. The efficacy of preoperative instruction in reducing anxiety following gynaecological surgery: a case control study. World journal of surgical oncology 2011; 9:38. https://doi.org/10.1186/1477-7819-9-38. 
[26] Sayah, M. (2013). Endoscopy and nursing cares. Site of nurse of the hospital of Ghaemshahr http://ghaemnursing.persianblog.ir/post/656.

[27] Seda, P. E. H. L., Van, N. O, Mehmet Koruk, Y. P., Van, O. O., \& Gulfien, M. T. (2011). Effect of providing information to the patient about upper gastrointestinal endoscopy on the patient's perception, compliance and anxiety level associated with the procedure. Turk J Gastroenterol, 22(1), 10 https://doi.org/10.4318/tjg.2011.0150.

[28] Shaban, F. M., \& Ghadery, S. H. (2018). Clinical Teaching Competences of Nursing Demonstrators at Faculty of Nursing Post Intervention program. Tanta Scientific Nursing Journal, 14(2), 32-55. https://doi.org/10.21608/tsnj.2018.69017.

[29] Reeve, K. L., Shumaker, C. J., Yearwood, E. L., Crowell, N. A., \& Riley, J. B. (2013). Perceived stress and social support in undergraduate nursing students' educational experiences. Nurse education today, 33(4), 419-424. https://doi.org/10.1016/j.nedt.2012.11.009.

[30] Shekari, R., \& Salehi, S. (2016). Review of the Impact of Nursing Care before Endoscopy on Anxiety and Stress and Depression and Pain of the Elderly Patients Visiting Esfahan's Al-Zahra Hospital in 2015. International Journal of Medical Research \& Health Sciences, 5(5), 164-172. https://www.ijmrhs.com/abstract/review-of-the-impact-of-nursing-care-before-endoscopy-on-anxiety-and-stress-and-depression-and-pain-of-theelderly-patie-3538.

[31] Thomas, S., \& Sugirtha, V. (2015). Effectiveness of structured teaching programme on knowledge and anxiety of patients undergoing endoscopy at a gastroenterology center of a tertiary care hospital. Anxiety, 1(O3X1), O2X1. https://www.ncbi.nlm.nih.gov/pubmed/30744253.

[32] Uzbeck M, Quinn C, Saleem I, Cotter P, Gilmartin JJ, O"Keeffe ST. Randomized controlled trial of the effect of standard and de-tailed risk disclosure prior to bronchoscopy on peri-procedure anxiety and satisfaction. Thorax 2009 Mar; 64(3):224-7. https://doi.org/10.1136/thx.2008.101220.

[33] YeganehKhah, M., Mohammadi, F., Khankah, H., Rahgozar, M. (2008). The impact of back massage with the slow stroke method on the anxiety of the elderly. Rehabilitation, 8)3): 14-20. http://rehabilitationj.uswr.ac.ir/article-1-176-en.html. 